\title{
Assessing Physical Activity and Sleep in Axial Spondyloarthritis: Measuring the Gap
}

\author{
Atul Deodhar · Lianne S. Gensler • Marina Magrey • Jessica A. Walsh • \\ Adam Winseck · Daniel Grant · Philip J. Mease
}

Received: August 22, 2019 / Published online: October 31, 2019

(C) The Author(s) 2019

\begin{abstract}
Patients with axial spondyloarthritis (axSpA) frequently report pain, stiffness, fatigue, and sleep problems, which may lead to impaired physical activity. The majority of reported-on measures evaluating physical activity and sleep disturbance in axSpA are self-reported questionnaires, which can be impacted by patient recall
\end{abstract}

Enhanced digital features To view enhanced digital features for this article go to https://doi.org/10.6084/ m9.figshare.9959021.

\section{A. Deodhar $(\bowtie)$}

Oregon Health \& Science University, Portland, OR, USA

e-mail: deodhara@ohsu.edu

\section{S. Gensler}

University of California San Francisco, San

Francisco, CA, USA

\section{Magrey}

Case Western Reserve University, MetroHealth

System, Cleveland, OH, USA

\section{J. A. Walsh}

University of Utah and Salt Lake City Veterans

Affairs Medical Center, Salt Lake City, UT, USA

A. Winseck · D. Grant

Novartis Pharmaceuticals Corporation, East

Hanover, NJ, USA

P. J. Mease

Swedish Medical Center and University of

Washington, Seattle, WA, USA (reporting bias). One objective measure, polysomnography, has been employed to evaluate sleep in patients with axSpA; however, it is an intrusive measure and cannot be used over the long term. More convenient objective measures are therefore needed to allow for the longterm assessment of both sleep and physical activity in patients' daily lives. Wearable technology that utilizes actigraphy is increasingly being used for the objective measurement of physical activity and sleep in various therapy areas, as it is unintrusive and suitable for continuous tracking to allow longitudinal assessment. Actigraphy characterizes sleep disruption as restless movement while sleeping, which is particularly useful when studying conditions such as axSpA in which chronic pain and discomfort due to stiffness may be evident. Studies have also shown that actigraphy can effectively assess the impact of disease on physical activity. More research is needed to establish the usefulness of objective monitoring of sleep and physical activity specifically in axSpA patients over time. This review summarizes the current perspectives on physical activity and sleep quality in patients with axSpA, and the possible role of actigraphy in the future to more accurately evaluate the impact of treatment interventions on sleep and physical activity in axSpA.

Funding: Novartis Pharmaceuticals Corporation.

Plain Language Summary: Plain language summary available for this article. 
Keywords: Actigraphy; Ankylosing spondylitis; Axial spondyloarthritis; Fatigue; Physical activity; Polysomnography; Radiographic axial spondyloarthritis; Rheumatology; Sleep disturbance

\section{Key Summary Points}

Patients with axial spondyloarthritis (axSpA) frequently report pain, stiffness, fatigue, and sleep problems, which may lead to impaired physical activity

The majority of measures for sleep and physical activity used in this patient population are subjective and limited by patient recall, reporting bias, and relatively short study intervals

Actigraphy will enable unintrusive and objective monitoring of sleep and physical activity in patients with axSpA over longer periods of time

Importantly, actigraphy may be used to evaluate the impact of treatment interventions on physical activity and sleep, allowing for identification of appropriate management strategies in patients with axSpA

Enhanced insight into sleep disturbance and impaired physical activity, and association with treatment changes in the long term, will enable healthcare providers to better understand patient variability and identify potential opportunities to address axSpA-related drivers of sleep disturbance and physical inactivity

\section{PLAIN LANGUAGE SUMMARY}

Axial spondyloarthritis is a type of inflammatory arthritis. It mainly affects the spine, but can also affect peripheral joints, tendons, and ligaments. Over time, the spine can become progressively stiff and painful due to the inflammation caused by the immune system's attack. Symptoms often improve with exercise, and therefore a key component of the management and treatment of axSpA is physical activity. However, levels of physical activity are often lower in those with axSpA, and this can have a negative impact on pain, function, and sleep quality.

To appropriately support people with axSpA, we need to understand the long-term effects of reduced physical activity and disturbed sleep. One way to do this is to measure physical activity and sleep, and here we look at the ways we can measure both of these in people with axSpA. This includes the use of tools such as questionnaires and wearable technology or devices, similar to Fitbits or pedometers. We particularly focus on wearable technology and how it may be used to assess the impact of different treatments on sleep and physical activity in people with axSpA.

\section{INTRODUCTION}

Axial spondyloarthritis (axSpA) is an inflammatory arthritis of the sacroiliac joints and spine, commonly presenting with chronic back pain [1]. Subgroups of axSpA include the prototype ankylosing spondylitis (AS), which is defined by the presence of definite radiographic sacroiliitis (also known as radiographic axSpA) [1], and non-radiographic axSpA (nr-axSpA), which represents an early form of the disease with a low to no burden of radiographic damage $[2,3]$. The 1984 modified New York classification criteria for AS use conventional radiographs of the sacroiliac joints to assess structural damage [4], whereas the Assessment of SpondyloArthritis international Society (ASAS) classification criteria for axSpA, developed in 2009 , can be used to classify axSpA even in the absence of sacroiliac joint damage on radiographs [5]. As axSpA refers to a spectrum of disease, this review will use this terminology throughout; however, it should be noted that most of the studies covered in this review 
focused on patients with AS, whereas more recent cohorts include patients with nr-axSpA.

Pain, stiffness, fatigue, and disturbed sleep are major concerns in patients with axSpA [6], and are associated with impaired physical activity. Studies show that poor sleep is related to depressed mood and increased stress [7], and correlates with poor quality of life, pain, and disease activity in patients with axSpA [8]. The location and spread of pain with axSpA have also been shown to be different between genders and are related to worse clinical outcomes, with women experiencing increased pain in the thoracic and cervicothoracic junction body regions [9].

This review explores the current literature concerning the methods used to evaluate physical activity-defined as any bodily movement produced by skeletal muscles that results in energy expenditure, of which exercise is just one component-and sleep in axSpA, including subjective and objective measures. The use of wearable technology [10] and how this will aid our future understanding of sleep and physical activity in patients with axSpA will also be a focus.

\section{METHODS}

\section{Literature and Search Strategy}

An author kick-off call led to the development of a top-line manuscript outline, on which authors submitted references deemed of interest. Following this, a focused PubMed literature search was performed March 12, 2018. Only articles published in English were included. The data were not limited by a publication date range. Searches included terms such as "physical activity," "sleep," "ankylosing spondylitis," "axial spondyloarthritis," "pain," and "actigraphy." The full text of relevant articles was evaluated for specific data relating to sleep and physical activity in patients with axSpA, and the technology involved. Only those deemed of relevance to the objectives of this study were included.

\section{Compliance with Ethics Guidelines}

This article is a literature review based on previously conducted studies. All procedures performed in studies involving human participants that were cited in this review were in accordance with the ethical standards of the institutional and/or national research committee and with the 1964 Helsinki Declaration and its later amendments or comparable ethical standards, as reported in the primary reports.

\section{RESULTS}

\section{Current Perspectives on Physical Activity in $\operatorname{axSpA}$}

The benefits of physical activity for the management of axSpA have long been recognized; regular exercise was recommended in the first set of Assessment of SpondyloArthritis International Society-European League Against Rheumatism (ASAS-EULAR) guidelines developed in 2006 [11]. In a Cochrane review, exercise and physical activity demonstrated small beneficial effects on physical function, spinal mobility, and patient global assessments in axSpA [12]. Another systematic review found that therapeutic exercise improved physical function, disease activity, pain, stiffness, joint mobility, and cardiovascular performance in adult patients with axSpA [13]. A systematic review also evaluated the impact of an aerobic fitness program over standard physiotherapy on disease activity and functional status in axSpA [14]. The meta-analysis showed no additional benefit of aerobic exercise over standard physiotherapy in terms of Bath Ankylosing Spondylitis Disease Activity Index (BASDAI) and Bath Ankylosing Spondylitis Functional Index (BASFI) scores [14]. Finally, in a multicenter, randomized trial of 100 axSpA patients, a 12-week high-intensity cardiorespiratory and strength exercise program reduced disease activity, as assessed by Ankylosing Spondylitis Disease Activity Score (ASDAS) and BASDAI, and improved both physical function, as assessed by BASFI, and cardiovascular health, as measured by maximal test on a treadmill walking uphill 
until exhaustion according to the modified Balke protocol (peak oxygen uptake: $\mathrm{VO}_{2 \text { peak }}$ $\mathrm{ml} / \mathrm{kg} / \mathrm{min}$ ), in patients with axSpA [15].

Although the efficacy of physical activity for axSpA is well documented, there is much less information available for nr-axSpA. In a study of 46 patients with axSpA who underwent a 6-month education and intensive exercise program, similar clinical efficacy was observed in both nr-axSpA and AS patients [16]. In a followup study in the same patient cohort, exercise therapy improved global disease activity in both AS and nr-axSpA subgroups [17].

The 2019 American College of Rheumatology/Spondylitis Association of America/ Spondyloarthritis Research and Treatment Network recommendations for patients with active axSpA note that physical therapy is strongly recommended, with supervised exercise being preferred over more passive options such as massage, ultrasound, and heat [18]. Physical therapy and unsupervised back exercises are also recommended for patients with active or stable axSpA [18]. Similarly, the 2016 ASAS-EULAR recommendations for axSpA state that patients should be encouraged to exercise regularly, and that physical therapy should be considered [19].

Although treatment guidelines advocate the inclusion of physical activity for the optimal management of axSpA [18-21], specific guidance about the amount of exercise required to produce a beneficial effect is lacking [22]. Global recommendations by the World Health Organization (WHO) state that all adults should engage in at least $150 \mathrm{~min}$ of moderate-intensity or at least $75 \mathrm{~min}$ of vigorous-intensity aerobic physical activity each week or an equivalent combination of moderate- and vigorous-intensity activity [23]. One study showed that physical function, health-related quality of life, and disease activity were improved in patients with SpA (including those with axSpA) who met the WHO recommendations for physical activity [24]. However, reports suggest that the majority of patients with axSpA fail to meet such recommendations [25], and that exercise levels in these patients tend to be lower than those in the general population $[22,25]$.
Objective measurements of physical activity, such as pedometers and accelerometers, track an individual's movement. Studies investigating physical activity in axSpA have utilized technology-based assessments, allowing for the use of an unbiased tool in the patient's own environment [26-28]. Swinnen and colleagues measured physical activity during five consecutive days using ambulatory monitoring (SenseWear armband) in 40 patients with axSpA and 40 age- and gender-matched healthy controls. Patients with axSpA displayed lower physical activity versus controls, and these differences were not influenced by self-reported disease activity [26]. A prospective observational study assessed physical activity continuously over 3 months in 79 patients with axSpA using a connected activity tracker, and disease flares were self-assessed weekly. The authors confirmed that persistent flares were related to a moderate decrease in physical activity. They also concluded that activity trackers may give indirect information on disease activity [27]. In another study, the authors also showed that wearable activity trackers allow longitudinal assessment of physical activity in axSpA, with only $27 \%$ of patients meeting the WHO recommendations [28]. Mobile activity trackers appear acceptable to patients and their use should be further explored as motivational tools to improve physical activity in axSpA patients [28]. In the prospective, observational ActConnect study, confirmed axSpA patients had their physical activity assessed continuously by the number of steps per minute over 3 months using a consumer-grade activity tracker. Flares were assessed weekly and machine-learning techniques were applied to the data [29]. Patient-reported flares were found to be associated with reduced physical activity [29]. Selfmanagement mobile health (mHealth) apps have also been proposed to offer patients realtime feedback to help them keep track of disease-related parameters, better adhere to medication schemes, and engage in physical therapy [30]. Data from 31 interviews with chronic arthritis patients showed a strong preference for mHealth features, which enabled them to keep better track of their condition, report these data to their healthcare professional, and receive 
Table 1 Subjective self-reported questionnaires and tools to assess physical activity in axial spondyloarthritis

\begin{tabular}{|c|c|c|}
\hline Physical activity measurement tool & Description & $\begin{array}{l}\text { Population } \\
\text { used for tool } \\
\text { validation }\end{array}$ \\
\hline $\begin{array}{l}\text { Health-Enhancing Physical Activity criteria } \\
\text { (HEPA) }\end{array}$ & $\begin{array}{l}\text { Reflects any form of physical activity that is } \\
\text { advantageous to the health and functional } \\
\text { capacity of the individual. Questionnaires such as } \\
\text { SQUASH are used to assess HEPA [67] }\end{array}$ & $\begin{array}{l}\text { Healthy } \\
\text { subjects }\end{array}$ \\
\hline $\begin{array}{l}\text { Long-Form International Physical Activity } \\
\text { Questionnaire (IPAQ-LF) }\end{array}$ & $\begin{array}{l}\text { 31-item questionnaire assessing several different } \\
\text { types of physical activity (occupational, } \\
\text { household and gardening, transport, and leisure } \\
\text { time) in an average week over the past month } \\
{[31,69]}\end{array}$ & $\begin{array}{l}\text { Healthy } \\
\text { subjects } \\
\text { Patients with } \\
\text { axSpA }\end{array}$ \\
\hline $\begin{array}{l}\text { Short-Form International Physical Activity } \\
\text { Questionnaire (IPAQ-SF) }\end{array}$ & 9-item questionnaire based on the IPAQ-LF [69] & \\
\hline Office in Motion Questionnaire (OIMQ) & $\begin{array}{l}\text { Covers domestic, work, and sports activities, with } \\
\text { the patient recalling the past } 7 \text { days [72] }\end{array}$ & \\
\hline Baecke Physical Activity Questionnaire & $\begin{array}{l}\text { Work, sports, and non-sports leisure activities are } \\
\text { assessed, with the number of months per year and } \\
\text { hours per week recorded [68] }\end{array}$ & $\begin{array}{l}\text { Patients with } \\
\text { hip disorders }\end{array}$ \\
\hline Short Questionnaire to Assess Health (SQUASH) & $\begin{array}{l}\text { Several types of activity assessed including } \\
\text { commuting, work and household activities, and } \\
\text { leisure time. Patients refer to an average week } \\
\text { over the past few months [31] }\end{array}$ & $\begin{array}{l}\text { Healthy } \\
\text { subjects } \\
\text { Patients with } \\
\text { axSpA }\end{array}$ \\
\hline Questionnaire for Arthritis Dialogue (QuAD) & $\begin{array}{l}\text { Covers beliefs about psychological factors, genetic } \\
\text { factors, physical activity, diet, lifestyle factors, and } \\
\text { miscellaneous beliefs. No timescale specified } \\
{[31,32]}\end{array}$ & $\begin{array}{l}\text { Patients with } \\
\text { RA or axSpA }\end{array}$ \\
\hline $\begin{array}{l}\text { Fear of Movement and (Re)Injury (FOM/R[I]) } \\
\text { beliefs, measured with the Tampa Scale for } \\
\text { Kinesiophobia 11-item version (TSK-11) }\end{array}$ & $\begin{array}{l}\text { Covers beliefs about activity limitations relative to } \\
\text { disease activity and spinal mobility [33] }\end{array}$ & $\begin{array}{l}\text { Patients with } \\
\text { axSpA }\end{array}$ \\
\hline
\end{tabular}

axSpA axial spondyloarthritis, HEPA Health-Enhancing Physical Activity criteria, IPAQ-LF Long-Form International Physical Activity Questionnaire, IPAQ-SF Short-Form International Physical Activity Questionnaire, OIMQ Office in Motion Questionnaire, $R A$ rheumatoid arthritis, SQUASH Short Questionnaire to Assess Health

tailored information based on disease-related health data specific to their type of arthritis [30].

However, assessment of physical activity using subjective measurement instruments, such as self-reported questionnaires and activity logs [27], is more common, with validation in healthy controls [31] (Table 1). The Short
Questionnaire to Assess Health (SQUASH), Long-Form International Physical Activity Questionnaire (IPAQ-LS), Questionnaire for Arthritis Dialogue (QuAD), and Fear of Movement and (Re)Injury (FOM/R[I]) beliefs, measured with the Tampa Scale for Kinesiophobia 11-item version (TSK-11), have also been 
validated in axSpA [31-33]. The SQUASH and IPAQ-LS questionnaires assess different forms of physical activity, such as sports and domestic activities, through patients recalling the duration/level of activity [31]. The 21-item QuAD includes four items on physical activity [32]. Patient beliefs regarding their disease were wide ranging. The belief that physical activity had a negative impact on the disease was associated with anxiety and helplessness about the disease, and poor patient education. However, patients with axSpA were less likely to believe that their disease was caused by smoking, and more likely to believe that physical activity could improve their disease status [32]. FOM/R(I) (TSK-11) was shown to be a promising tool to explain fearful beliefs about activity limitations relative to disease activity and spinal mobility in axSpA [33].

\section{Current Perspectives on Sleep in axSpA}

Disturbed sleep, especially during the latter part of the night, is a common problem in patients with axSpA, leading patients to get up and walk around to relieve the symptoms. This contributes to daytime fatigue [8], which is likely to impact the ability and willingness of patients to engage in physical activity. It has been reported that $54.8 \%$ of patients with AS experience sleep disturbances [34], and patients with fatigue are likely to have more than three awakenings in the night and generally feel more tired the next morning [35]. Other sleep problems that may also occur in axSpA patients include poor sleep quality, sleep-onset insomnia, difficulty awakening, and obstructive sleep apnea syndrome [36].

Like physical activity, the impact of axSpA on patients' sleep can be assessed using objective or subjective instruments [37]. Polysomnography (PSG) is the widely used "gold standard" objective measure of sleep, which involves the monitoring of physical and psychological processes in a sleep laboratory, allowing for detailed assessment of sleep architecture and sleep-disordered breathing [38]. There are very few studies that comprehensively investigate sleep in axSpA patients using PSG
$[37,39,40]$. It is expensive, requires monitoring in a sleep laboratory [38], is often intrusive to sleep [41], and is only suitable for use over short timeframes, meaning that data and conclusions can be misinterpreted, for example, in instances where sleep problems do not occur every night. Subjective measures that have been used in axSpA are self-reported questionnaires related to sleep, or those that include questions about sleep with respect to general health or quality of life, which have been validated in both healthy controls and in those with AS or nr-axSpA (see Table 2) [42-49].

Only one placebo-controlled study has assessed sleep quality in patients with active axSpA using a validated instrument; this study investigated the efficacy of golimumab in reducing sleep disturbance using the Jenkins Sleep Evaluation Questionnaire (JSEQ) [8]. Treatment with golimumab resulted in significant improvements in JSEQ scores from baseline at week 14 and week 24 compared with placebo. Improvements in sleep quality (as assessed by PSG) significantly correlated with improvements in Short Form-36 (SF-36), BASFI, night back pain, BASDAI, and total back pain scores, as well as in measures of fatigue from the BASDAI and vitality from the SF-36 [8].

\section{Objective Measures of Sleep and Physical Activity}

There is a need for objective, more convenient, and less intrusive objective measures that would allow for long-term assessment of sleep disturbances and their impact on physical activity, and physical activity in patients' daily lives, outside of the clinic. Actigraphy, a technology based on small sensors, is increasingly being used in both interventional and non-interventional studies to evaluate physical activity and sleep. The use of mechanical movement sensors to evaluate psychological disorders in a pediatric population in the 1950s was the first reported medical use of actigraphy [50]. Over time, with advances in the consumer electronics markets-within which consumer-grade activity monitors have been popularized by Fitbit and Garmin-actigraphy devices have 
Table 2 Subjective self-reported questionnaires and tools to assess sleep in axial spondyloarthritis [37]

\begin{tabular}{|c|c|c|}
\hline $\begin{array}{l}\text { Sleep measurement } \\
\text { tool }\end{array}$ & Description & Population used for tool validation \\
\hline $\begin{array}{l}\text { Epworth Sleepiness } \\
\text { Scale (ESS) }\end{array}$ & $\begin{array}{l}\text { 8-item questionnaire measuring daytime } \\
\text { sleepiness and evaluating the possibility of } \\
\text { falling asleep in everyday situations [ } 42]\end{array}$ & $\begin{array}{l}\text { Healthy controls } \\
\text { Patients with a range of sleep disorders }\end{array}$ \\
\hline $\begin{array}{l}\text { Jenkins Sleep } \\
\text { Evaluation } \\
\text { Questionnaire } \\
\text { (JSEQ) }\end{array}$ & $\begin{array}{l}\text { 4-item questionnaire measuring frequency and } \\
\text { severity of sleep disturbance in the past } 30 \text { days } \\
{[43]}\end{array}$ & $\begin{array}{l}\text { Male air traffic controllers } \\
\text { Patients } 6 \text { months after cardiac surgery }\end{array}$ \\
\hline $\begin{array}{l}\text { Medical Outcomes } \\
\text { Study Sleep } \\
\text { questionnaire } \\
\text { (MOS) }\end{array}$ & $\begin{array}{l}\text { 12-item questionnaire assessing sleep quality and } \\
\text { quantity over the past month }[44,45]\end{array}$ & Persons aged $\geq 14$ years \\
\hline $\begin{array}{l}\text { Pittsburgh Sleep } \\
\text { Quality Index } \\
\text { (PSQI) }\end{array}$ & $\begin{array}{l}19 \text { questions measuring sleep disturbance over } \\
\text { the past month [46] }\end{array}$ & $\begin{array}{l}\text { Healthy controls (good sleepers) } \\
\text { Bad sleepers (depressed, sleep disorders) }\end{array}$ \\
\hline $\begin{array}{l}\text { Uppsala Sleep } \\
\text { Inventory (USI) }\end{array}$ & $\begin{array}{l}\text { 80-item questionnaire measuring sleep and sleep- } \\
\text { related issues [ } 47]\end{array}$ & $\begin{array}{l}\text { Healthy controls (random sample in age group } \\
45-64 \text { years) }\end{array}$ \\
\hline $\begin{array}{l}\text { Ankylosing } \\
\text { Spondylitis Quality } \\
\text { of Life Index } \\
\text { (ASQoL) }\end{array}$ & $\begin{array}{l}\text { 18-item questionnaire assessing quality of life. } \\
\text { One question assesses sleep; Q5 = “It's } \\
\text { impossible to sleep" [48] }\end{array}$ & Patients with AS \\
\hline $\begin{array}{l}\text { Nottingham Health } \\
\text { Profile (NHP) }\end{array}$ & $\begin{array}{l}\text { 2-part questionnaire involving subjective self- } \\
\text { assessment of health. Part I relates to sleep [49] }\end{array}$ & $\begin{array}{l}\text { Healthy controls } \\
\text { Selected controls (patients with minor non- } \\
\text { acute conditions, fracture victims, patients } \\
\text { with peripheral vascular disease, chronically ill } \\
\text { elderly, patients with osteoarthrosis, pregnant } \\
\text { women, "fit" elderly, mine-rescue workers) }\end{array}$ \\
\hline
\end{tabular}

Reprinted by permission from Springer, Rheumatol Int, Prevalence and factors associated with disturbed sleep in patients with ankylosing spondylitis and non-radiographic axial spondyloarthritis: a systematic review, S. Leverment et al. (C) Springer-Verlag Berlin Heidelberg 2016

ASQoL Ankylosing Spondylitis Quality of Life Index, axSpA axial spondyloarthritis, ESS Epworth Sleepiness Scale, JSEQ Jenkins Sleep Evaluation Questionnaire, MOS Medical Outcomes Study Sleep questionnaire, NHP Nottingham Health Profile, PSQI Pittsburgh Sleep Quality Index, USI Uppsala Sleep Inventory

become unintrusive, making them more convenient and suitable for continuous wear. Modern actigraphy techniques use digital accelerometers to measure body movements, typically at the wrist or waist. Assessment of data from an accelerometer typically involves integration of acceleration data with respect to time [10], in which continual and prolonged actigraphic recording of daytime and nocturnal activity provides real-time data that can be stored long term [50]. Examples of actigraphy traces taken from healthy controls, those with 
chronic pain receiving opioid medication, and those receiving treatment other than opioid medication are shown in Fig. 1 [51]. Traces can be further processed and activity levels analyzed to quantitatively assess sleep quality, including the determination of measures such as sleep latency, sleep efficiency, awake times, and awake time duration [51].

Medical-grade actigraphy devices (such as the Actiwatch [Philips N.V.] and ActiGraph Link GT9X [ActiGraph, LLC.]) have been used as alternatives to PSG [52] (Fig. 2). Although actigraphic assessment of sleep is not comparable to PSG for clinical diagnosis of sleep-disordered breathing or sleep architecture-specific disorders, it has been used extensively to effectively assess more general sleep parameters [53]. Actigraphy is increasingly being used to evaluate the impact of treatment interventions on physical activity and sleep. Actigraphic assessment of sleep is particularly helpful when studying conditions such as chronic pain or pruritus, in which sleep disruption is characterized by restless movement $[51,54]$, and has been shown to be an effective measure in prospective studies assessing the impact of treatment interventions on both daytime physical activity and sleep in patients with heart failure, atopic dermatitis, rheumatoid arthritis, osteoarthritis, and other chronic diseases [55-59].

Importantly, actigraphy has been used to effectively assess the impact of rheumatic disease on physical activity, in which the relationship between flares and physical activity has been evaluated [27]. During a 3-month study of rheumatoid arthritis and axSpA, physical activity of 170 patients (91 with rheumatoid arthritis, 79 with axSpA) was assessed by the number of steps per day using an activity tracker, while disease flares were self-assessed using a weekly questionnaire. Results indicated that frequent flares were shorter in duration and related to decreases in physical activity. This study was the first to longitudinally and objectively explore the relationship between disease activity and physical activity in axSpA [27].

Actigraphy has also been used in studies evaluating musculoskeletal and neuropathic pain. In one study, the impact of celecoxib on osteoarthritis ( $n=63)$ was assessed using patient-reported outcomes, captured by a daily eDiary, and actigraphy [58]. While objective assessment of changes in physical activity demonstrated a meaningful response to treatment, self-reported questionnaires, with recall periods of either $24 \mathrm{~h}$ or 1 week, were not statistically significant and subject to a larger placebo effect [58]. In another study evaluating the effect of transdermal fentanyl on physical activity over 16 weeks in patients with neuropathic pain [60], the use of actigraphy showed a $37 \%$ increase in daytime activity levels in the final 8 weeks of the study with treatment versus baseline measurements.

In the rheumatology clinic, the use of US Food and Drug Administration-approved actigraphy devices might provide a large volume of invaluable real-time data that could be integrated with electronic records, allowing for continuous tracking of a patient's well-being, helping to guide the course of treatment in patients with axSpA. Utilizing such data, healthcare providers would be able to better understand patient variability, and identify potential opportunities to address axSpA-related drivers of sleep disturbance and physical inactivity. In conjunction with patient-reported outcomes, actigraphy could also be used to establish correlations between disease activity and pain levels with daytime physical activity and sleep.

\section{Limitations of Assessing Physical Activity and Sleep in axSpA}

Subjective methods, such as self-reported questionnaires and logs, are the most common tools for assessing patients' daily physical activity and sleep quality. Although these tools are inexpensive and broadly accessible to investigators, they have limitations. Research has shown that reporting bias [61] and patient recall [62] have an impact on questionnaire scores. One study in patients with axSpA showed that exertion and pain experienced while performing activities appeared to have a greater negative influence on their BASFI score than their actual performance-based measures of physical function, 


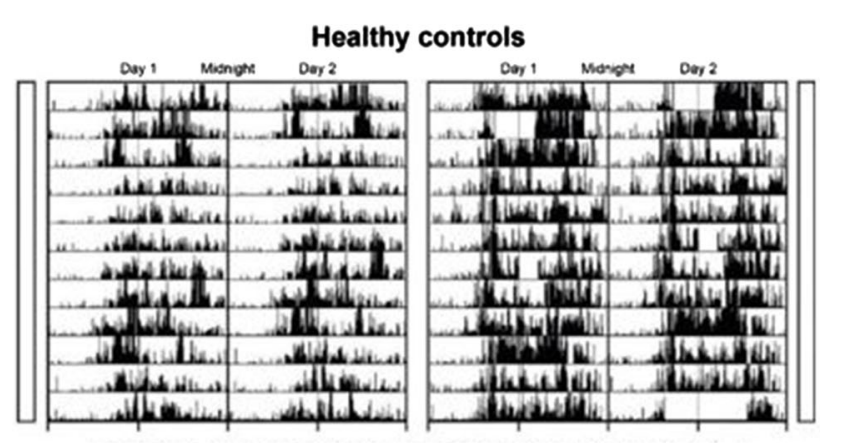

Patients with chronic pain taking opioid medication
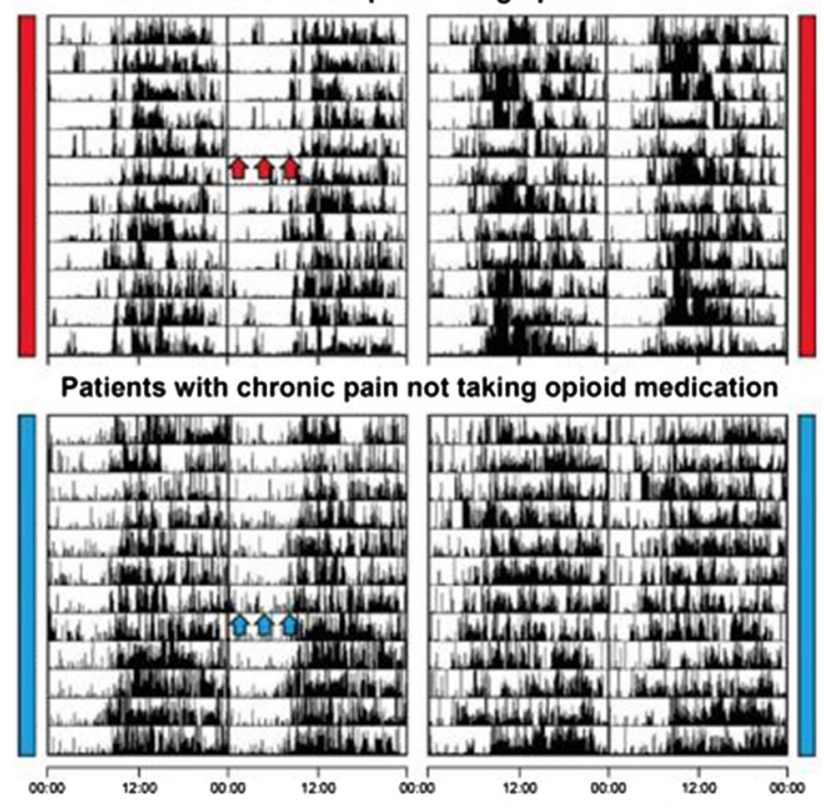

Fig. 1 Example actigraphy traces. Black bars indicate activity levels, with intensity on the vertical axis and time on the horizontal axis. In this sample, actigraphy shows continuous activity during the night in patients not on opioid medication (blue bar/arrows) while patients on

leading to reporting bias [63]. In addition, several self-reported questionnaires used to measure physical activity and sleep in axSpA require patient recall over 1 month [31, 37], which may lead to inaccuracy unless a detailed diary is kept by the patient.

Self-reported scores for physical activity do not substitute for objective measures, and accurate assessments should include both selfreported and objective measures [64]. Similarly, there is currently no validated sleep measure for patients with axSpA, and there are inconsistencies between the different sleep scales and opioid medication are least active during the night (red bar/arrows). Figure resized from Robertson, et al. (2016) [51]. (C) 2016 J. A. Robertson et al. Sleep disturbance in patients taking opioid medication for chronic back pain. Anaesthesia. 2016;71:1296-1307. Used under CC BY 4.0

methods used to define "poor sleep" [37]. Therefore, more objective measures are needed to allow for accurate assessment of sleep quality in this patient population.

When considering actigraphy, although allowing for long-term assessment of physical activity and sleep, it can overestimate sleep and underestimate wake time in certain patient groups [50]. Since actigraphy technology uses lack of movement as a proxy for sleep, those who are awake but motionless would be classified as asleep. This would incorrectly underestimate the number and severity of sleep 
(a)

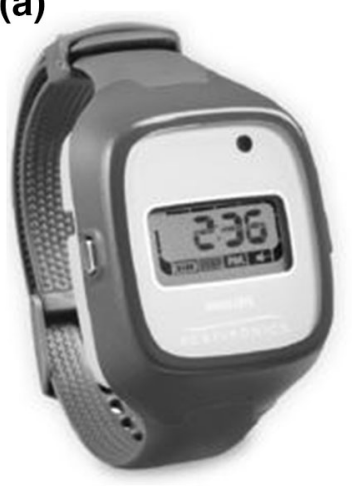

(b)

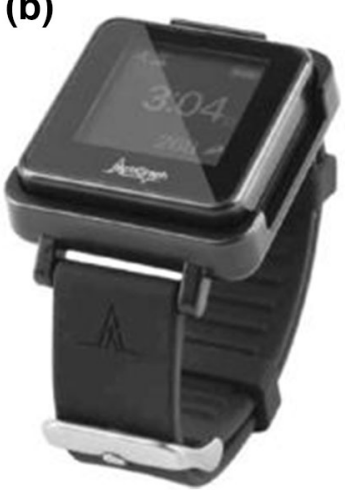

Fig. 2 Examples of wearable medical-grade actigraphy devices, including a Actiwatch Spectrum watch [70], and b the ActiGraph Link GT9X [71]

disturbances [50]. Furthermore, while actigraphy is an objective measure of movement, it is unable to detect the level of energy expenditure or exertion related to physical activity [65].

\section{Clinical Implications}

The use of newer tools and techniques, such as actigraphy, will contribute to the better understanding of sleep disturbance and physical activity over time, and aid in the interpretation of associated therapeutic outcomes. This will provide healthcare providers with data to support the optimization of an individual patient's treatment regimen based on the knowledge obtained from the patient themselves, augmented by the information gathered from others. With such ability and insight, it is likely that further improvements in sleep and physical activity may be achieved through refining patient management and treatment, and may allow for long-term changes in the overall health status of these patients.

\section{DISCUSSION AND CONCLUSIONS}

Sleep disturbance secondary to pain, stiffness, and proinflammatory mediators [66] is a major symptom in patients with axSpA, which may lead to impaired physical activity. Regular physical activity is recommended in a number of guidelines on the nonpharmacological management of axSpA [11, 18-21]; physical activity has been shown to improve physical function, mobility, disease activity, quality of life, and cardiovascular performance in this group of patients $[12,13]$. However, exercise levels tend to be lower in these patients $[22,25]$. There is a need for convenient measures that allow for the long-term assessment of both sleep and physical activity in patients' daily lives. The majority of measures for sleep and physical activity used in this patient population are subjective and limited by patient recall, reporting bias, and relatively short study intervals [31, 37, 67-69]. Actigraphy will enable unintrusive, objective monitoring of sleep and physical activity in patients with axSpA, over longer periods of time $[27,53,56-58]$, though further research to fully evaluate its utility and value for use in everyday clinical practice is needed. Importantly, actigraphy may be used to evaluate the impact of treatment interventions on physical activity and sleep. This will allow for better understanding of sleep disturbance and impaired physical activity in patients with axSpA, the recognition of patient variability, and the identification of potential opportunities to address axSpA-related drivers of sleep disturbance and physical activity.

\section{ACKNOWLEDGEMENTS}

Funding. Financial support for the generation of this manuscript and funding of the 
journals Rapid Service Fees has been provided by Novartis Pharmaceuticals Corporation, East Hanover, NJ, United States. All authors had full access to all of the data in this study and take complete responsibility for the integrity of the data and accuracy of the data analysis.

Medical Writing, Editorial, and Other Assistance. The authors thank Shelley Maria Lindley, PhD, of SciMentum Ltd, London, UK, for providing medical writing/editorial support, funded by Novartis Pharmaceuticals Corporation, East Hanover, New Jersey, United States, in accordance with Good Publication Practice (GPP3) guidelines (http://www.ismpp.org/ gpp3).

Authorship. All named authors meet the International Committee of Medical Journal Editors (ICMJE) criteria for authorship for this article, take responsibility for the integrity of the work as a whole, and have given their approval for this version to be published.

Disclosures. Atul Deodhar: grants from Novartis during the conduct of the study; has received research grants from: BMS, Eli Lilly, GlaxoSmithKline, Novartis, Pfizer and UCB, and has received honoraria for consulting with AbbVie, Amgen, BMS, Boehringer Ingelheim, Eli Lilly, Galapagos, GlaxoSmithKline, Janssen, Novartis, Pfizer and UCB, outside the submitted work. Lianne S. Gensler: grants from Novartis and Pfizer, personal fees from AbbVie, Galapagos, Janssen, Lilly, Pfizer and UCB, outside the submitted work. Marina Magrey: grants from AbbVie, Amgen, personal fees from Eli Lilly and Novartis, and grants and personal fees from UCB, during the conduct of the study; research grants from AbbVie, Amgen, and UCB and served as a consultant to Novartis, outside the submitted work. Jessica A. Walsh: grants and personal fees from AbbVie, Amgen, Lilly, Novartis, and Pfizer and served as a consultant to UCB, outside the submitted work. Adam Winseck: employment and stock from Novartis. Daniel Grant: employment and stock from Novartis. Philip J. Mease: has received grant support from AbbVie, Amgen, BMS, Janssen, Lilly, Novartis, Pfizer, SUN, UCB; has worked as a paid consultant for AbbVie, Amgen, BMS, Boehringer Ingelheim, Celgene, Galapagos, Gilead, Janssen, Lilly, Novartis, Pfizer, SUN, UCB; has been paid as a speaker for AbbVie, Amgen, BMS, Celgene, Genentech, Janssen, Lilly, Novartis, Pfizer, UCB, outside the submitted work.

Compliance with Ethics Guidelines. This article is a literature review based on previously conducted studies. All procedures performed in studies involving human participants that were cited in this review were in accordance with the ethical standards of the institutional and/or national research committee and with the 1964 Helsinki Declaration and its later amendments or comparable ethical standards, as reported in the primary reports.

Data Availability. Data sharing is not applicable to this article as no datasets were generated or analyzed during the current study.

Open Access. This article is distributed under the terms of the Creative Commons Attribution-NonCommercial 4.0 International License (http://creativecommons.org/licenses/ by-nc/4.0/), which permits any noncommercial use, distribution, and reproduction in any medium, provided you give appropriate credit to the original author(s) and the source, provide a link to the Creative Commons license, and indicate if changes were made.

\section{REFERENCES}

1. Terenzi R, Monti S, Tesei G, Carli L. One year in review 2017: spondyloarthritis. Clin Exp Rheumatol. $2018 ; 36: 1-14$.

2. Dubash S, McGonagle D, Marzo-Ortega H. New advances in the understanding and treatment of axial spondyloarthritis: from chance to choice. Ther Adv Chronic Dis. 2018;9:77-87.

3. Malaviya AN, Rawat R, Agrawal N, Patil NS. The nonradiographic axial spondyloarthritis, the radiographic axial spondyloarthritis, and ankylosing spondylitis: the tangled skein of rheumatology. Int J Rheumatol. 2017;2017:1824794. 
4. van der Linden S, Valkenburg HA, Cats A. Evaluation of diagnostic criteria for ankylosing spondylitis. A proposal for modification of the New York criteria. Arthritis Rheum. 1984;27:361-8.

5. Rudwaleit M, Landewé R, van der Heijde D, Listing J, Brandt J, Braun J, et al. The development of Assessment of SpondyloArthritis international Society classification criteria for axial spondyloarthritis (part I): classification of paper patients by expert opinion including uncertainty appraisal. Ann Rheum Dis. 2009;68:770-6.

6. Ward MM. Health-related quality of life in ankylosing spondylitis: a survey of 175 patients. Arthritis Care Res. 1999;12:247-55.

7. Da Costa D, Zummer M, Fitzcharles MA. Determinants of sleep problems in patients with spondyloarthropathy. Musculoskeletal Care. 2009; 7:143-61.

8. Deodhar A, Braun J, Inman RD, Mack M, Parasuraman S, Buchanan J, et al. Golimumab reduces sleep disturbance in patients with active ankylosing spondylitis: results from a randomized, placebocontrolled trial. Arthritis Care Res. 2010;62:1266-71.

9. Swinnen TW, Dankaerts W, Westhovens R, de Vlam K. THU0711-HPR Widespread pain in axial spondyloarthritis: clinical importance and gender differences. Ann Rheum Dis. 2018;77:1784.

10. Chen KY, Bassett DR Jr. The technology of accelerometry-based activity monitors: current and future. Med Sci Sports Exerc. 2005;37:S490-500.

11. Zochling J, van der Heijde D, Burgos-Vargas R, Collantes E, Davis JCJ, Dijkmans B, et al. ASAS/ EULAR recommendations for the management of ankylosing spondylitis. Ann Rheum Dis. 2006;65:442-52.

12. Dagfinrud H, Kvien TK, Hagen KB. Physiotherapy interventions for ankylosing spondylitis. Cochrane Database Syst Rev 2008:CD002822.

13. O'Dwyer T, O'Shea F, Wilson F. Exercise therapy for spondyloarthritis: a systematic review. Rheumatol Int. 2014;34:887-902.

14. Verhoeven F, Guillot X, Prati C, Mougin F, Tordi N, Demougeot $C$, et al. Aerobic exercise for axial spondyloarthritis-its effects on disease activity and function as compared to standard physiotherapy: a systematic review and meta-analysis. Int J Rheum Dis. 2019;22:234-41.

15. Sveaas SH, Bilberg A, Berg IJ, Provan SA, Rollefstad $\mathrm{S}$, Semb AG, et al. High intensity exercise for 3 months reduces disease activity in axial spondyloarthritis (axSpA): a multicentre randomised trial of 100 patients. Br J Sports Med 2019.

16. Levitova A, Hulejova H, Spiritovic M, Pavelka K, Senolt L, Husakova M. Clinical improvement and reduction in serum calprotectin levels after an intensive exercise programme for patients with ankylosing spondylitis and non-radiographic axial spondyloarthritis. Arthritis Res Ther. 2016;18:275.

17. Husakova M, Siebuhr AS, Pavelka K, Spiritovic M, Bay-Jensen A, Levitova A. Changes of patient-reported outcomes and protein fingerprint biomarkers after exercise therapy for axial spondyloarthritis. Clin Rheumatol. 2019;38:173-9.

18. Ward MM, Deodhar A, Gensler LS, Dubreuil M, Yu D, Khan MA, et al. 2019 Update of the American College of Rheumatology/Spondylitis Association of America/Spondyloarthritis Research and Treatment Network Recommendations for the Treatment of Ankylosing Spondylitis and Nonradiographic Axial Spondyloarthritis. Arthritis Care Res. 2019. https://doi.org/10.1002/acr.24025 (Epub ahead of print).

19. van der Heijde D, Ramiro S, Landewé R, Baraliakos X, Van den Bosch F, Sepriano A, et al. 2016 update of the ASAS-EULAR management recommendations for axial spondyloarthritis. Ann Rheum Dis. 2017;76:978-91.

20. Spanish Society of Rheumatology. Clinical Practice Guideline for the Treatment of Patients with Axial Spondyloarthritis and Psoriatic Arthritis [Spanish Society of Rheumatology website]. 2015. https:// www.ser.es/wp-content/uploads/2016/06/

ENGLISH_updated_GPC_Treatment_ SpondyloArthritis.pdf. Accessed 14 Jan 2019.

21. Ozgocmen S, Akgul O, Altay Z, Altindag O, Baysal $\mathrm{O}$, Calis $\mathrm{M}$, et al. Expert opinion and key recommendations for the physical therapy and rehabilitation of patients with ankylosing spondylitis. Int J Rheum Dis. 2012;15:229-38.

22. O'Dwyer T, O'Shea F, Wilson F. Physical activity in spondyloarthritis: a systematic review. Rheumatol Int. 2015;35:393-404.

23. World Health Organization. Global recommendations on physical activity for health [WHO website]. 2010. http://apps.who.int/iris/bitstream/10665/ 44399/1/9789241599979_eng.pdf. Accessed 14 Jan 2019.

24. Haglund E, Bergman S, Petersson IF, Jacobsson LT, Strombeck B, Bremander A. Differences in physical activity patterns in patients with spondylarthritis. Arthritis Care Res. 2012;64:1886-94. 
25. O'Dwyer T, O'Shea F, Wilson F. THU0636-HPR significantly reduced physical activity in adults with ankylosing spondylitis: a cross-sectional controlled study. Ann Rheum Dis. 2015;74:1321.

26. Swinnen TW, Scheers T, Lefevre J, Dankaerts W, Westhovens R, de Vlam K. Physical activity assessment in patients with axial spondyloarthritis compared to healthy controls: a technology-based approach. PLoS One. 2014;9:e85309.

27. Jacquemin C, Molto A, Servy H, Sellam J, Foltz V, Gandjbakhch F, et al. Flares assessed weekly in patients with rheumatoid arthritis or axial spondyloarthritis and relationship with physical activity measured using a connected activity tracker: a 3-month study. RMD Open. 2017;3:e000434.

28. Jacquemin C, Servy H, Molto A, Sellam J, Foltz V, Gandjbakhch F, et al. Physical activity assessment using an activity tracker in patients with rheumatoid arthritis and axial spondyloarthritis: prospective observational study. JMIR mHealth uHealth. 2018;6:e1.

29. Gossec L, Guyard F, Leroy D, Lafargue T, Seiler M, Jacquemin C, et al. Detection of flares by decrease in physical activity, collected using wearable activity trackers, in rheumatoid arthritis or axial spondyloarthritis: an application of machinelearning analyses in rheumatology. Arthritis Care Res 2018.

30. Geuens J, Geurts L, Swinnen TW, Westhovens R, Abeele VV. Mobile health features supporting selfmanagement behavior in patients with chronic arthritis: mixed-methods approach on patient preferences. JMIR mHealth uHealth. 2019; $7: \mathrm{e} 12535$.

31. Arends S, Hofman M, Kamsma YPT, van der Veer E, Houtman PM, Kallenberg CGM, et al. Daily physical activity in ankylosing spondylitis: validity and reliability of the IPAQ and SQUASH and the relation with clinical assessments. Arthritis Res Ther. 2013;15:R99.

32. Gossec L, Berenbaum F, Chauvin P, Hudry C, Cukierman G, De Chalus T, et al. Development and application of a questionnaire to assess patient beliefs in rheumatoid arthritis and axial spondyloarthritis. Clin Rheumatol. 2018;37:2649-57.

33. Swinnen TW, Vlaeyen JWS, Dankaerts W, Westhovens R, de Vlam K. Activity limitations in patients with axial spondyloarthritis: a role for fear of movement and (re)injury beliefs. J Rheumatol. 2018;45:357-66.

34. Günaydin R, Goksel Karatepe A, Çeşmeli N, Kaya T. Fatigue in patients with ankylosing spondylitis: relationships with disease-specific variables, depression, and sleep disturbance. Clin Rheumatol. 2009;28:1045-51.

35. Missaoui B, Revel M. Fatigue in ankylosing spondylitis. Ann Readapt Med Phys 2006;49:305,308, 389-391.

36. Batmaz I, Sarıyıldız MA, Dilek B, Bez Y, Karakoç M, Cevik R. Sleep quality and associated factors in ankylosing spondylitis: relationship with disease parameters, psychological status and quality of life. Rheumatol Int. 2013;33:1039-45.

37. Leverment S, Clarke E, Wadeley A, Sengupta R. Prevalence and factors associated with disturbed sleep in patients with ankylosing spondylitis and non-radiographic axial spondyloarthritis: a systematic review. Rheumatol Int. 2017;37:257-71.

38. Roebuck A, Monasterio V, Gederi E, Osipov M, Behar J, Malhotra A, et al. A review of signals used in sleep analysis. Physiol Meas. 2013;35:R1-57.

39. Karatas G, Bal A, Yuceege M, Firat H, Gurcay E, Ardic S, et al. Evaluation of sleep quality in patients with ankylosing spondylitis and efficacy of antiTNF- $\alpha$ therapy on sleep problems: a polisomnographic study. Int J Rheum Dis. 2018;21:1263-9.

40. Mantua J, Gravel N, Spencer R. Reliability of sleep measures from four personal health monitoring devices compared to research-based actigraphy and polysomnography. Sensors. 2016;16:646.

41. Kosmadopoulos A, Sargent C, Darwent D, Zhou X, Roach GD. Alternatives to polysomnography (PSG): a validation of wrist actigraphy and a partial-PSG system. Behav Res Methods. 2014;46:1032-41.

42. Johns MW. A new method for measuring daytime sleepiness: the Epworth sleepiness scale. Sleep. 1991;14:540-5.

43. Jenkins CD, Stanton BA, Niemcryk SJ, Rose RM. A scale for the estimation of sleep problems in clinical research. J Clin Epidemiol. 1988;41:313-21.

44. Hays RD, Stewart AL. Sleep measures. In: Stewart $\mathrm{AL}$, Ware JE, editors. Measuring functioning and well-being: the medical outcomes study approach. Durham: Duke University Press; 1992. p. 235-59.

45. Viala-Danten M, Martin S, Guillemin I, Hays RD. Evaluation of the reliability and validity of the Medical Outcomes Study sleep scale in patients with painful diabetic peripheral neuropathy during an international clinical trial. Health Qual Life Outcomes. 2008;6:113.

46. Buysse DJ, Reynolds CF 3rd, Monk TH, Berman SR, Kupfer DJ. The Pittsburgh Sleep Quality Index: a 
new instrument for psychiatric practice and research. Psychiatry Res. 1989;28:193-213.

47. Hetta J, Almqvist M, Ågren H, Hambert G, Liljenberg B, Roos BE. Prevalence of sleep disturbances and related symptoms in a middle-aged Swedish population. In: Koella WP, Ruther E, Schulz H, editors. Sleep '84. Stuttgart: Gustav Fischer Verlag; 1985. p. 373-6.

48. Doward LC, Spoorenberg A, Cook SA, Whalley D, Helliwell PS, Kay LJ, et al. Development of the ASQOL: a quality of life instrument specific to ankylosing spondylitis. Ann Rheum Dis. 2003;62:20-6.

49. Hunt SM, McEwen J, McKenna SP. Measuring health status: a new tool for clinicians and epidemiologists. J R Coll Gen Pract. 1985;35:185-8.

50. Martin JL, Hakim AD. Wrist actigraphy. Chest. 2011;139:1514-27.

51. Robertson JA, Purple RJ, Cole P, Zaiwalla Z, Wulff K, Pattinson KT. Sleep disturbance in patients taking opioid medication for chronic back pain. Anaesthesia. 2016;71:1296-307.

52. Ancoli-Israel S, Martin JL, Blackwell T, Buenaver L, Liu L, Meltzer LJ, et al. The SBSM guide to actigraphy monitoring: clinical and research applications. Behav Sleep Med. 2015;13:S4-38.

53. Marino M, Li Y, Rueschman MN, Winkelman JW, Ellenbogen JM, Solet JM, et al. Measuring sleep: accuracy, sensitivity, and specificity of wrist actigraphy compared to polysomnography. Sleep. 2013;36:1747-55.

54. Bender BG, Leung SB, Leung DY. Actigraphy assessment of sleep disturbance in patients with atopic dermatitis: an objective life quality measure. J Allergy Clin Immunol. 2003;111:598-602.

55. Redfield MM, Anstrom KJ, Levine JA, Koepp GA, Borlaug BA, Chen $\mathrm{HH}$, et al. Isosorbide mononitrate in heart failure with preserved ejection fraction. N Engl J Med. 2015;373:2314-24.

56. Nemoto O, Furue M, Nakagawa H, Shiramoto M, Hanada R, Matsuki S, et al. The first trial of CIM331, a humanized antihuman interleukin-31 receptor A antibody, in healthy volunteers and patients with atopic dermatitis to evaluate safety, tolerability and pharmacokinetics of a single dose in a randomized, double-blind, placebo-controlled study. Br J Dermatol. 2016;174:296-304.

57. Clarke LL, Wilson S, Kirwan JR. Using actigraphy to measure sleep patterns in rheumatoid arthritis: a pilot study in patients taking night-time prednisone. Musculoskeletal Care. 2013;11:179-85.
58. Trudeau J, Van Inwegen R, Eaton T, Bhat G, Paillard F, Ng D, et al. Assessment of pain and activity using an electronic pain diary and actigraphy device in a randomized, placebo-controlled crossover trial of celecoxib in osteoarthritis of the knee. Pain Pract. 2015;15:247-55.

59. Kop WJ, Lyden A, Berlin AA, Ambrose K, Olsen C, Gracely RH, et al. Ambulatory monitoring of physical activity and symptoms in fibromyalgia and chronic fatigue syndrome. Arthritis Rheum. 2005;52:296-303.

60. Agarwal S, Polydefkis M, Block B, Haythornthwaite J, Raja SN. Transdermal fentanyl reduces pain and improves functional activity in neuropathic pain states. Pain Med. 2007;8:554-62.

61. Sallis JF, Saelens BE. Assessment of physical activity by self-report: status, limitations, and future directions. Res Q Exerc Sport. 2000;71:S1-14.

62. Wang MY, Hung HL, Tsai PS. The sleep log and actigraphy: congruency of measurement results for heart failure patients. J Nurs Res. 2011;19:173-80.

63. van Weely SF, van Denderen JC, Steultjens MP, van der Leeden M, Nurmohamed MT, Dekker J, et al. Moving instead of asking? Performance-based tests and BASFI-questionnaire measure different aspects of physical function in ankylosing spondylitis. Arthritis Res Ther. 2012;14:R52.

64. Millner JR, Barron JS, Beinke KM, Butterworth RH, Chasle BE, Dutton LJ, et al. Exercise for ankylosing spondylitis: an evidence-based consensus statement. Semin Arthritis Rheum. 2016;45:411-27.

65. Terrier P, Aminian K, Schutz Y. Can accelerometry accurately predict the energy cost of uphill/downhill walking? Ergonomics. 2001;44:48-62.

66. Hurtado-Alvarado G, Pavon L, Castillo-Garcia SA, Hernandez ME, Dominguez-Salazar E, VelazquezMoctezuma J, et al. Sleep loss as a factor to induce cellular and molecular inflammatory variations. Clin Dev Immunol. 2013;2013:801341.

67. Mack DE, Wilson PM, Gunnell KE, Gilchrist JD, Kowalski KC, Crocker PR. Health-enhancing physical activity: associations with markers of well-being. Appl Psychol Health Well Being. 2012;4:127-50.

68. Ono R, Hirata S, Yamada M, Nishiyama T, Kurosaka M, Tamura Y. Reliability and validity of the Baecke physical activity questionnaire in adult women with hip disorders. BMC Musculoskelet Disord. 2007;8:61.

69. Craig CL, Marshall AL, Sjöström M, Bauman AE, Booth ML, Ainsworth BE, et al. International physical activity questionnaire: 12-country 
reliability and validity. Med Sci Sports Exerc. 2003;35:1381-95.

70. Philips N.V. Actiwatch. 2019. http://www. actigraphy.com/assets/actiwatch-plus-18f176316ae 8e34b9a364d48063c6f7cd029e7636fad631e7c0af4e 3012de874.png. Accessed 21 Aug 2019.

71. ActiGraph, LLC. ActiGraph Link. 2019. https:// www.actigraphcorp.com/actigraph-link/. Accessed 21 Aug 2019.
72. Mäder URS, Martin BW, Schutz Y, Marti B. Validity of four short physical activity questionnaires in middle-aged persons. Med Sci Sports Exerc. 2006;38:1255-66. 